\title{
APOE $\varepsilon 4$ influences the manifestation of Alzheimer's disease in adults with Down's syndrome
}

\author{
SHOUMITRO DEB, JOHN BR AGANZA, NADINE NORTON, \\ HYWEL WILLIAMS, PATRICK G. KEHOE, JULIE WILLIAMS \\ and MICHAEL J. OWEN
}

\section{Background Recent studies of the relationship between the apolipoprotein $\mathrm{E}$ (APOE) gene and Alzheimer's disease in adults with Down's syndrome have revealed inconsistent results.}

\begin{abstract}
Aims To assess the role of the APOE gene in the manifestation of Alzheimer's disease in adults with Down's syndrome.
\end{abstract}

\section{Method We studied the APOE genotypes of 24 adults with dementia and 33 non-demented adults with Down's syndrome over 35 years of age, and an additional group of 164 non-learning disabled adults. We also carried out a meta-analysis of all previously published studies of association between APOE and Down's syndrome, incorporating the current data.}

\section{Results We observed a non-significant excess of $A P O E \varepsilon 4$ and a reduction of $\varepsilon 2$ in adults with dementia compared with non- demented adults with Down's syndrome in our sample. However, meta-analysis showed a significantly higher frequency of $\varepsilon 4$ in adults with dementia compared with non-demented adults with Down's syndrome (odds ratio $=2.02,95 \% \mathrm{Cl}$ 1.33-3.07, $P=0.00$ I), but no significant reduction in the frequency of $\varepsilon 2$.}

Conclusions The APOE $\varepsilon 4$ allele acts as a risk factor for the age-specific manifestation of Alzheimer's disease in people with Down's syndrome.

Declaration of interest This study was partly funded by the Medical Research Council (grant no. 9810900).
Autopsy studies have shown that adults with Down's syndrome aged 40 years and above almost universally exhibit Alzheimer's disease neuropathology (Mann, 1988), a fact that is supported by neuroimaging studies (Deb et al, 1992). Saunders et al (1993) reported an association between APOE \&4 and late-onset Alzheimer's disease. A number of studies have produced inconsistent support for $A P O E \varepsilon 4$ as a risk factor and $A P O E \varepsilon 2$ as a protective factor against Alzheimer's disease in people with Down's syndrome (Prasher et al, 1997; Tyrell et al, 1998). Our study examined whether the age specific manifestation of Alzheimer's disease in adults with Down's syndrome was influenced by risk factors such as age, $A P O E$ status, and genotype for an intronic polymorphism in the $P S-1$ gene, which is also reputedly associated with late onset Alzheimer's disease (Kehoe et al, 1996). We examined the APOE polymorphism in three groups: (a) a populationbased sample of adults with dementia with Down's syndrome aged 35 years and over; (b) an elderly group of non-demented adults with Down's syndrome drawn from the same population-based sample; and (c) a group of normal non-demented adults selected for intelligence, collected from the same geographical area as the first two groups. We also carried out a meta-analysis comprising all published studies of association between the APOE gene and Alzheimer's disease in adults with Down's syndrome, incorporating the data from the current study.

\section{METHOD}

\section{Subjects}

The names of all known adults with Down's syndrome over the age of 35 years were collected from the clinicians and staff of Community Learning Disability Teams in all five Health Districts in South Wales.
Subjects were assessed for Alzheimer's disease using the ICD-10 (World Health Organization, 1992) criteria in accordance with the guidelines produced by an international consensus panel established under the auspices of the Ageing Special Interest Group of the International Association for the Scientific Study of Intellectual Disabilities (IASSID) (Aylward et al, 1997). The diagnosis of dementia was further supported by using two observer-rated questionnaires, namely the Dementia Questionnaire for Mentally Retarded Persons (DMR) (Evenhuis, 1992) and the Dementia Scale for Down's syndrome (DSDS) (Gedye, 1995). Both questionnaires are reported to have good inter-rater reliability and internal validity (Evenhuis, 1992; Gedye, 1995). Deb \& Braganza (1999) have recently reported a positive correlation between diagnosis of dementia by a clinician in adults with Down's syndrome and diagnosis carried out according to the DSDS criteria (specificity $=0.89$, sensitivity $=0.85$ ), and the DMR criteria (specificity $=0.92$, sensitivity $=0.92$ ).

The age of onset of dementia was determined by asking the carers of adults with Down's syndrome when clinical symptoms of dementia were first noticed. Diagnosis of Down's syndrome was based on the characteristic clinical features and no karyotyping was carried out. The level of intellectual disability was determined either on the basis of IQ scores or the assessment of adaptive behaviours.

We excluded adults with Down's syndrome who showed medical, psychiatric, neurological or laboratory characteristics not related to Alzheimer's disease, but which might explain their mental deterioration, in particular severe hearing loss, untreated hypothyroidism and depression $(n=2)$. In all, 24 adults with Down's syndrome who had a diagnosis of Alzheimer's disease were included in this study. We ascertained a second group of 33 individuals, identified as the oldest adults from a list of non-demented adults with Down's syndrome. As the prevalence of dementia in adults with Down's syndrome tends to increase with age (Lai \& Williams, 1989), it is anticipated that those who have lived longer without manifesting clinical dementia have least risk factors for developing dementia, and therefore provides an appropriate group for comparison. Finally, a control group of 164 non-demented adults representative of the local population and unselected for intelligence were used $(54 \%$ 
Table I APOE allele frequency in different groups

\begin{tabular}{lcrr}
\hline & $\varepsilon 2, n(\%)$ & $\varepsilon 3, n(\%)$ & $\varepsilon 4 n(\%)$ \\
\hline Adults with dementia with Down's syndrome $(n=24)$ & 0 & $40(83.0)$ & $8(17.0)$ \\
Non-demented adults with Down's syndrome $(n=33)$ & $3(4.5)$ & $57(86.5)$ & $6(9.0)$ \\
All adults with Down's syndrome $(n=57)$ & $3(2.6)$ & $97(85.0)$ & $14(12.3)$ \\
Non-learning disabled control group $(n=164)$ & $23(7.0)$ & $264(80.0)$ & $41(13.0)$ \\
\hline
\end{tabular}

male, mean age 38.27 years, s.d. $=12.16$ years).

\section{Genotyping}

Both the adults with dementia and the nondemented adults with Down's syndrome, and the non-demented, non-learning disabled control group were genotyped for both the APOE and PS-1 polymorphisms using standard techniques (Wenham et al, 1991; Wragg et al, 1996). For a detailed description of PS-1 data see Deb et al (1998), but data in relation to a multivariate analysis of risk factors in relation to Alzheimer's disease in Down's syndrome will be presented in this paper. The study was performed with the approval of the local research ethics committee and written, informed consent was obtained from participants or carers where appropriate.

\section{Statistical analysis}

The $\chi^{2}$ and Fisher's exact tests were used to test for association between $A P O E$ and Alzheimer's disease in Down's syndrome. Multiple logistic regression analysis was also carried out to estimate the relative influence of risk factors such as age, gender, APOE and PS -1 genotype on the development of Alzheimer's disease in adults with Down's syndrome. The Woolf method (Woolf, 1955) was used to perform a meta-analysis of association between APOE genotype and Alzheimer's disease in Down's syndrome. A Mann-Whitney $U$-test was used to test for a relationship between APOE and the age of onset of Alzheimer's disease in Down's syndrome.
A probability of less than one in 20 $(P<0.05)$ was regarded as significant in all statistical analyses.

\section{RESULTS}

\section{Current study}

The age range of the total cohort of adults with Down's syndrome was between 35 and 72 years (mean 51, s.d. $=7.8$ years). Twenty-three $(40.4 \%)$ were aged between 35 and 49 years, and $34(59.6 \%)$ were 50 years or older. The age range of Down's syndrome adults with dementia was between 35 and 71 (mean 54, s.d.=7.24), and those without dementia was between 35 and 72 years (mean 49, s.d. $=7.55$ ). Thirty-one $(54.4 \%)$ were male and $26(45.6 \%)$ were female. Thirteen $(22.8 \%)$ had mild (IQ 70-50), 37 (65\%) moderate (IQ 50-35), and seven severe $(12.2 \%)$ intellectual disability (IQ <35). There was no statistically significant difference in the proportion of subjects with different degrees of severity of learning disability between the adults with dementia and the non-demented adults with Down's syndrome.

The distribution of APOE alleles among the three study groups is shown in Table 1, while the distribution of APOE genotypes is presented in Table 2. No statistically significant differences were observed in any of the inter-group comparisons shown in Table 1 and Table 2. However, a higher frequency of $\varepsilon 4$ allele $(17 \% v$. $\left.9 \% ; \chi^{2}=1.4, P=0.2\right)$ and a lower frequency of $\varepsilon 2$ allele $(0 \% v .4 .5 \%)(P=0.26$ : Fisher's exact test) were observed among adults with Down's syndrome with dementia compared with those without (see Table 1).

Adults with Down's syndrome were divided up into two age groups (below 50 years, and 50 years and older), and two gender groups (male and female). This was done because of Sekijama et al's (1998) finding that the frequency of $\varepsilon 4$ allele in Down's syndrome adults with Alzheimer's disease under 50 years was significantly higher $(28.6 \%)$, and Schupf et al's (1998) finding of earlier onset of Alzheimer's disease in men with Down's syndrome. The APOE $\varepsilon 4$ allele frequency between the adults with dementia and the non-demented adults with Down's syndrome according to the age- and gendergroups are presented in Table 3. None of the inter-group comparisons in Table 3 was statistically significant.

A multiple logistic regression analysis was carried out in the whole cohort of adults with Down's syndrome using the presence of dementia as a dependent variable and age, gender, $A P O E$ status, and $P S-1$ polymorphism as covariates. The presence of dementia was only significantly related to age in adults with Down's syndrome.

To assess the influence of APOE $\varepsilon 4$ on the age of onset of dementia in adults with Down's syndrome we compared the mean age of onset between those who had an $\varepsilon 4$ allele and those who did not. The mean age of onset of dementia among $\varepsilon 4$ positive cases (at least one $\varepsilon 4$ allele) was 51 years and 53 years for those who did not have an $\varepsilon 4$ allele. A comparison of ages of onset in those with and without an $\varepsilon 4$ allele was not statistically significant.

\section{Meta-analysis}

Prasher et al (1997) presented a meta-analysis of the data collected from all the known published papers in addition to their own data in relation to APOE status in adults with Down's syndrome with and without Alzheimer's disease. We have added data from two other recent studies (Sekijama et al, 1998; Tyrell et al, 1998), and our current

Table 2 APOE genotypes in different groups

\begin{tabular}{lcccccc}
\hline & $\varepsilon 4 \varepsilon 4 n(\%)$ & $\varepsilon 4 \varepsilon 2 n(\%)$ & $\varepsilon 4 \varepsilon 3 n(\%)$ & $\varepsilon 3 \varepsilon 3 n(\%)$ & $\varepsilon 3 \varepsilon 2 n(\%)$ & $\varepsilon 2 \varepsilon 2 n(\%)$ \\
\hline Adults with dementia with Down's syndrome $(n=24)$ & 0 & 0 & $8(33.3)$ & $16(66.7)$ & 0 \\
Non-demented adults with Down's syndrome $(n=33)$ & 0 & 0 & $6(18.2)$ & $24(72.7)$ & $3(9.1)$ & 0 \\
All adults with Down's syndrome $(n=57)$ & 0 & 0 & $14(24.6)$ & $40(70.2)$ & $3(5.2)$ & 0 \\
Non-learning disabled control group $(n=164)$ & $3(1.8)$ & $3(1.8)$ & $32(19.5)$ & $108(65.8)$ & $16(9.7)$ & $2(1.2)$ \\
\hline
\end{tabular}


Table 3 Frequency of $A P O E \varepsilon 4$ and $\varepsilon 2$ alleles in adults with Down's syndrome according to age and gender group

\begin{tabular}{|c|c|c|c|c|}
\hline & \multicolumn{2}{|c|}{$\varepsilon 4$ frequency } & \multicolumn{2}{|c|}{$\varepsilon 2$ frequency } \\
\hline & Demented subjects, $n(\%)$ & Non-demented subjects, $n$ (\%) & Demented subjects, $n(\%)$ & Non-demented subjects, $n(\%)$ \\
\hline Age $<50$ years $(n=23)$ & $2(25)$ & $2(33.3)$ & 0 & I (33.3) \\
\hline Age $\geqslant 50$ years $(n=34)$ & $6 \quad(75)$ & $4(66.6)$ & 0 & $2(66.7)$ \\
\hline Male $(n=31)$ & $3(37.5)$ & $3(50)$ & 0 & $3(100)$ \\
\hline Female $(n=26)$ & $5(62.5)$ & $3(50)$ & 0 & 0 \\
\hline
\end{tabular}

study to those analysed by Prasher et al (1997) and this is presented in Table 4. However, we excluded Wisniewski et al's (1995) data, which were included in Prasher et al's (1997) meta-analysis, because unlike all the other studies they diagnosed Alzheimer's disease on the basis of neuropathological findings alone in the absence of any clinical data. The previous meta-analysis (Prasher et al, 1997) did not show a statistically significant difference in the distribution of $A P O E$ alleles between the adults with dementia and Down's syndrome and the non-demented adults with Down's syndrome. However, the metaanalysis in the current study showed a statistically significant excess of APOE $\varepsilon 4$ in Down's syndrome cases with Alzheimer's disease compared with those without (odds ratio $=2.02,95 \%$ CI $1.33-3.07, \chi^{2}=10.83$, $P=0.001)$ with no evidence of heterogeneity $(P=0.2)$. We did not observe a significantly lower rate of $A P O E \varepsilon 2$ allele frequency in Down's syndrome adults with Alzheimer's disease (odds ratio $=0.69,95 \%$
CI 0.35-1.37). The odds ratios along with 95\% CIs of those individual studies where a statistically significant excess of $A P O E$ $\varepsilon 4$ or reduction of $\varepsilon 2$ allele frequency was observed among adults with Down's syndrome with Alzheimer's disease are presented at the bottom of Table 4 .

\section{DISCUSSION}

\section{The current study}

We observed a higher frequency of the $A P O E \& 4$ allele among subjects with dementia and Down's syndrome compared with those without dementia, although this trend was not statistically significant. Similarly a slightly lower frequency of the protective $\varepsilon 2$ alleles was observed among the adults with dementia and Down's syndrome. The small cohort size of the current study reduced the statistical power for this study $(24 \%$ power at $5 \%$ level) to detect an effect size of that reported previously. However, in this study the age-matching of two groups of patients with Down's syndrome one of which had dementia, was done in such a way so as to increase its sensitivity and thus lessen the influence of this statistical weakness.

\section{Meta-analysis}

To increase the possibility of detecting small effect sizes, we collated data from all known published studies of association between APOE status in Down's syndrome and Alzheimer's disease. This was the method employed recently by Prasher et al (1997) that showed no evidence to support an involvement of APOE. However, the meta-analysis reported here, showed a statistically significant excess of the APOE $\varepsilon 4$ allele among the subjects with dementia when compared with the non-demented group of adults with Down's syndrome. However, we did not observe a significant reduction of $A P O E \varepsilon 2$ alleles among the adults with dementia and Down's syndrome.

Table 4 Meta-analysis of pooled data from reports on APOE allele frequency in adults with and without dementia (updated from Prasher et al's (1997) data)

\begin{tabular}{|c|c|c|c|c|c|c|c|c|}
\hline \multirow[t]{2}{*}{ Study } & \multicolumn{4}{|c|}{$\begin{array}{l}\text { Adults with Down's syndrome with dementia } \\
\qquad \text { (allele frequency) } n(\%)\end{array}$} & \multicolumn{4}{|c|}{$\begin{array}{l}\text { Adults with Down's syndrome without dementia } \\
\qquad \text { (allele frequency) } n(\%)\end{array}$} \\
\hline & Total & $\varepsilon 2$ & $\varepsilon 3$ & $\varepsilon 4$ & Total & $\varepsilon 2$ & $\varepsilon 3$ & $\varepsilon 4$ \\
\hline Royston et al (1994) & 34 & I (3.0) & $25(73.5)$ & $8(23.5)$ & 10 & $5(50.0)$ & $5(50.0)$ & 0 \\
\hline van Gool et al (1995) & 52 & $3(5.8)$ & $42(80.8)$ & $7(13.4)$ & 52 & $6(11.0)$ & $4 \mid(78.8)$ & $5(9.6)$ \\
\hline Martins et al (1995)' & 12 & I (8.3) & $7(58.3)$ & $4(33.4)$ & 34 & $5(14.7)$ & $28(82.4)$ & I (2.9) \\
\hline Lambert et al (1996) & 16 & I (6.2) & $13(81.3)$ & $2(12.5)$ & 54 & $7(13.0)$ & $40(74.0)$ & $7(13.0)$ \\
\hline Schupf et al $(1996)^{2}$ & 26 & 0 & $18(69.2)$ & $8(30.8)$ & 138 & $12(8.7)$ & $109(79.0)$ & $17(12.3)$ \\
\hline Prasher et al (1997) & 34 & $4(I I .8)$ & $28(82.3)$ & $2(5.9)$ & 166 & II (6.6) & I35 (8I.3) & $20(12.1)$ \\
\hline Tyrell et al (1998) & 62 & 0 & $51(82.3)$ & II (I7.7) & 120 & $10(8.3)$ & $97(80.8)$ & $13(10.9)$ \\
\hline Sekijima et al (1998) & 32 & $2(6.3)$ & $24(74.9)$ & $6(18.8)$ & 174 & $4(2.3)$ & $158(90.8)$ & $12(6.9)$ \\
\hline Current study & 48 & 0 & $40(83.3)$ & $8(16.7)$ & 66 & $3(4.5)$ & $57(86.4)$ & $6(9.1)$ \\
\hline Total group & 316 & $12(3.8)$ & $248(78.5)$ & $56(17.7)$ & 814 & $63(7.7)$ & $670(82.3)$ & $81(10)$ \\
\hline
\end{tabular}

$\varepsilon 4$ v. rest: I. Odds ratio $=16.50$ (95\% Cl I.62-168); 2 odds ratio=3.16 (95\% Cl I.19-8.39); 3. odds ratio $=3.12$ (95\% Cl I.08-9.03).

Meta-analysis, $\varepsilon 4$ v. rest: odds ratio $=2.02\left(95 \% \mathrm{Cl}\right.$ I.33-3.07), pooled $\chi^{2}=10.83, P=0.001$.

Meta-analysis, $\varepsilon 2 \mathrm{v}$. rest: odds ratio $=0.69(95 \% \mathrm{Cl} 0.35-1.37)$. 
Certain factors may have influenced the outcome of the meta-analysis in the current study as well as in Prasher et al's (1997) study. It is likely that the age difference in the cohorts used in the previous studies (Table 4) is a factor that may have introduced errors into the results of meta-analysis. The age range of subjects included in these studies varied, in that some used age 18 whereas others used age 35,40 and 50 respectively as the minimum age for inclusion in the study. If $A P O E$ is responsible for earlier age of onset of Alzheimer's disease, this differential rate of age range among the different cohorts will make the interpretation of meta-analysis difficult. The lack of appropriately matched control group is another likely source of bias. Only the current study, Tyrell et al's (1998) study and van Gool et al's (1995) study matched the dementia group with the non-dementia group. Prasher et al's (1997) study while not originally matched demonstrated no statistically significant difference between the two groups in the age and the gender distribution. The cohort size is also a likely source of error. Apart from the current study, only two other studies (see Table 4) included 20 or more adults with dementia in their cohort. Another source of error is the use of different diagnostic criteria for defining dementia in different studies. Some used formal tools like the DMR scale (Evenhuis, 1992) and Adaptive Behaviour Scale (Nihira et al, 1974), whereas others made their diagnosis on the basis of clinical findings alone.

\section{Age of onset of Alzheimer's disease}

In the current study, a regression analysis unequivocally showed an influence of ageing on the occurrence of Alzheimer's disease in adults with Down's syndrome. Age is a well-known risk factor for the development of Alzheimer's disease in both the general population and in the adults with Down's syndrome. This effect seems more pronounced among the adults with Down's syndrome. Some have suggested that age of death among adults with Down's syndrome is influenced by the APOE status. In Hardy et al's (1994) autopsy study, the Down's syndrome cases showing Alzheimer's disease neuropathology and who had an APOE $\varepsilon 4(n=10)$ allele, tended to die at a younger age (age of death ranged between 48 and 60 years, mean 54, s.d.=6) than those who had an $\varepsilon 2$ allele $(n=2)$ (age of death 69 and 76 years respectively). A similar trend was also reported by both Royston et al (1994) and Mann et al (1995) based on their small cohort studies. Some suggested that APOE status also influences the age of onset of Alzheimer's disease in the general population (Corder et al, 1993). However, the findings of the current study do not suggest such trend among cases of Down's syndrome. Considering the small cohort size included for the analysis of age of onset data in the current study, a Type II error is likely to influence the outcome. As early symptoms of Alzheimer's disease could be difficult to detect in adults with Down's syndrome, it is difficult to be precise about the exact age of onset of Alzheimer's disease in this cohort.

The frequency of APOE $\varepsilon 4$ allele distribution among the adults with dementia and Down's syndrome in different studies mentioned in Table 4 varied between $12.5 \%$ and $33.4 \%$, apart from Prasher et al's (1997) study, which showed a much lower $(5.9 \%)$ frequency than that expected in the general population. In contrast, the frequency of $A P O E \varepsilon 2$ alleles varied widely between $0 \%$ in the current study, and that of Schupf et al's (1996) and Tyrell et al's (1998), to the $11.8 \%$ observed in Prasher et al's (1997) study, which is higher than expected even for the general population. The frequency of $\varepsilon 2$ allele among the nondemented subjects with Down's syndrome was on average much higher than that expected in the general population, with a wide range between $2.3 \%$ in Sekijima et al's (1998) study and 50\% in Royston et al's (1994) study. Overall these data are indicative of $A P O E \varepsilon 4$ being a risk factor for the manifestation of Alzheimer's disease in adults with Down's syndrome.

\section{APOE $\varepsilon 4$ and Alzheimer's disease neuropathology in Down's syndrome}

The findings of autopsy studies of patients with Down's syndrome, however, show a somewhat unclear relationship between APOE $\varepsilon 4$ and Alzheimer's disease neuropathology in this population. For example, in Wisniewski et al's (1995) autopsy study of brains of 40 subjects with Down's syndrome (of whom 15 showed Alzheimer's disease neuropathology), only one 21-year-old subject had an APOE $\varepsilon 4$ allele ( $\varepsilon 3 \varepsilon 4$ genotype) and his brain did not show the Alzheimer's disease neuropathology. In Mann et al's (1995) study of 20 brains of subjects with Down's syndrome, all of whom showed Alzheimer's disease neuropathology, only $35 \%(n=7)$ had APOE $\varepsilon 4$ allele (one with $\varepsilon 2 \varepsilon 4$ and six with $\varepsilon 3 \varepsilon 4$ ). Similarly, in Hardy et al's (1994) series of 22 autopsy brains of subjects with Down's syndrome, all of whom showed Alzheimer's disease neuropathology, 45\% $(n=10)$ had APOE $\varepsilon 4$ (all with $\varepsilon 3 \varepsilon 4$ allele). Further research is needed to clarify this apparent discrepancy perhaps by using immunoneuropathological techniques. It is also important to explore the exact mechanism by which APOE $\varepsilon 4$ may influence the clinical manifestation of Alzheimer's disease in Down's syndrome subjects. However, it is well known that despite the increased risk associated with the $\varepsilon 4$ allele, the presence of $\varepsilon 4$ is neither necessary nor sufficient for the development of Alzheimer's disease (Blacker \& Tanzi, 1998).

\section{ACKNOWLEDGEMENTS}

We thank all the subjects and their carers for taking part in the study, Dr Frank Dunstan for his advice on statistical analysis and Mrs J. Wheeler for typing the manuscript.

\section{REFERENCES}

Aylward, E. H., Burt, D. B., Thorpe, L. J., et al (1997) Diagnosis of dementia in individuals with intellectual disability. Journal of Intellectual Disability Research, 4I, 15-164.

Blacker, D. \& Tanzi, R. E. (1998) The genetics of Alzheimer's disease. Archives of Neurology, 55, 294-296.

Corder, E. H., Saunders, A. M., Strittmater, W. J., et al (1993) Gene dose of apolipoprotein E-type 4 allele and the risk of Alzheimer's disease in late onset families. Science, 26I, 921-92.

Deb, S., de Silva, P. N., Gemmell, H. G., et al (1992) Alzheimer's disease in adults with Down's syndrome: the relationship between regional cerebral blood flow deficits and dementia. Acta Psychiatrica Scandinavica, 86 340-345.

_, Braganza, J., Owen, M., et al (1998) No significant association between a PS-I intronic polymorphism and dementia in Down's syndrome. Alzheimer's Report, I, 365-368.

_ \& _ (1999) Comparison of rating scales for the diagnosis of dementia in adults with Down's syndrome. Journal of Intellectual Disability Research, 43, 400-407.

Evenhuis, H. M. (1992) Evaluation of a screening instrument for dementia in aging mentally retarded persons. Journal of Intellectual Disability Research, 36 337-347.

Gedye, A. (1995) Dementia Scale for Down Syndrome Manual. Vancouver: Gedye Research and Consulting.

Hardy, J., Crook, R., Perry, R., et al (1994) Apo E genotype and Down's syndrome. Lancet, 343, 979-980.

Kehoe, P., Williams, J., Holmans, P., et al (1996) Association between a PS-I intronic polymorphism and late onset Alzheimer's disease. Neuroreport, 7 , $2155-2158$. 
Lai, F. \& Williams, R. S. (1989) A prospective study of Alzheimer's disease in Down syndrome. Archives of Neurology, 46, 849-853.

Lambert, J. C., Perez-Tur, J., Dupire, M. J., et al (1996) Analysis of APOE alleles impact in Down's syndrome. Neuroscience Letters, 200, 57-60.

Mann, D. M. A. (1988) Alzheimer's disease and Down's syndrome. Histopathology, 13, 125-137.

_ , Pickering-Brown, S. M., Siddons, M. A., et al (1995) The extent of amyloid deposition in brain in patients with Down's syndrome does not depend upon the apolipoprotein E genotype. Neuroscience Letters, 196 105-108.

Martins, R. N., Clarnette, R., Fisher, C., et al (1995) ApoE genotypes in Australia: Roles in early and late onset Alzheimer's disease and Down's syndrome. Neuroreport, 6, 1513-1516.

Nihira, K., Foster, R., Shellhaas, M., et al (1974) Adaptive Behavior Scale. Washington, DC: American Association on Mental Retardation.

Prasher, V. P., Chowdhury, T. A., Rowe, B. R., et al (1997) APOE genotype and Alzheimer's disease in adults with down syndrome: meta-analysis. American Journal on Mental Retardation, 102, 103-110.

Royston, M. C., Mann, D., Pickering-Brown, S. M., et al (1994) Apolipoprotein in E $\varepsilon 2$ allele promotes longevity and protects patients with Down syndrome from dementia. Neuroreport, 5, 2583-2585.

Saunders, A. M., Strittmater,W. J., Schmechel, D., et al (1993) Association of apolipoprotein E allele $\varepsilon 4$ with late-onset familial and sporadic Alzheimer's disease. Neurology, 43, 1467-1472.

Sekijima, Y., Ideda, S., Tokuda, T., et al (1998) Prevalence of dementia of Alzheimer type and apolipoprotein E phenotypes in aged patients with Down's syndrome. European Neurology, 39, 234-237.

Schupf, N., Kapell, D., Lee, J. E., et al (1996) Onset of dementia is associated with apolipoprotein E $\varepsilon 4$. Archives of Neurology, 40, 799-80I.

_ , _, Nightingale, B., et al (1998) Earlier onset of Alzheimer's disease in men with Down syndrome. Neurology, 50, 991-995.

Tyrell, J., Cosgrave, M., Hawi, Z., et al (1998) A protective effect of apolipoprotein $\mathrm{E} \varepsilon 2$ allele on dementia in Down's syndrome. Biological Psychiatry, 43, 397-400.

van Gool, W. A., Evenhuis, H. M. \& van Duijin, C. M. (1995) A case-controlled study of apolipoprotein $E$

\section{CLINICAL IMPLICATIONS}

APOE $\varepsilon 4$ allele influences the manifestation of Alzheimer's disease in adults with Down's syndrome.

- The role of APOE $\varepsilon 2$ allele in relation to Alzheimer's disease in adults with Down's syndrome is not clear.

- The influence of APOE \&4 allele on the age of onset of Alzheimer's disease in adults with Down's syndrome is not clear.

\section{LIMITATIONS}

The studies included in the meta-analysis used cohorts of different age groups.

The adults with Down's syndrome without Alzheimer's disease were not always matched in these studies.

- Criteria used for diagnosing Alzheimer's disease varied in different studies.

SHOUMITRO DEB, FRCPsych, JOHN BRAGANZA, MRCPsych, NADINE NORTON, BSc, HYWEL WILLIAMS, BSc, PATRICK G. KEHOE, PhD, JULIE WILLIAMS, PhD, MICHAEL OWEN, FRCPsych, Division of Psychological Medicine, University of Wales College of Medicine, Cardiff

Correspondence: Dr S. Deb, Division of Psychological Medicine, University of Wales College of Medicine, Heath Park, Cardiff CF4 4XN. Tel: 01222 562323. Fax: 0122 555047. E-mail Deb@Cardiff.ac.uk

(First received I5 June 1999, final revision 29 September 1999, accepted I October 1999)

genotypes in Alzheimer's disease associated with Down's syndrome. Annals of Neurology, 38, 225-230.

Wenham, P. R., Price, W. H. \& Blundell, G. (199I) Apolipoprotein E genotyping by one-stage PCR. Lancet, 337, II58-1159.

Wisniewski, T., Morelli, L., Wegiel, J., et al (1995) The influence of apolipoprotein E isotopes on Alzheimer's disease pathology in 40 cases of Down's syndrome. Annals of Neurology, 37, 136-138.
Woolf, B. (1955) On estimating the relation between blood group and disease. Annals of Human Genetics, 19 25I-253.

World Health Organization (1992) The Tenth Revision of the International Classification of Diseases and Related Disorders (ICD-10). Geneva: WHO.

\section{Wragg, M., Hutton, M. \& Talbot, C. (1996)}

Genetic association between intronic polymorphism in presenilin-I gene and late-onset Alzheimer's disease. ancet, 347, 509-512. 